\title{
O novo consenso da sociedade brasileira: democracia e igualdade
}

\author{
Elizabeth Balbachevsky \\ Departamento de Ciência Política \\ Universidade de São Paulo \\ Denilde Holzhacker \\ Faculdades Integradas Rio Branco \\ Escola Superior de Propaganda e Marketing
}

\begin{abstract}
Resumo: Este artigo investiga o grau de convergência das opiniões sustentadas pelas elites e pela população brasileira sobre as políticas de redução da desigualdade social e redução da pobreza. A literatura internacional sobre esse tema se divide entre aqueles que vêem uma divisão entre elite e massa em torno dessa questão, e aqueles supõem que as dificuldades enfrentadas pelas novas democracias para garantir o crescimento econômico e desenvolvimento social teriam favorecido a formação de um novo consenso social unindo elites e massas, onde as políticas de redução da pobreza e de desigualdade ocupam um lugar preeminente. Nossa análise comparou os resultados alcançados na pesquisa Estudo Eleitoral Brasileiro (CSES-ESEB) de 2010, com os dados coletados junto a uma amostra da elite brasileira em 2009. Os resultados da análise sustentam a hipótese de que é possível falar em um consenso amplo unindo a elite e a população em torno de uma agenda de políticas voltadas para a diminuição da desigualdade no país e para a erradicação da pobreza
\end{abstract}

Palavras chaves: elite, população, agenda política, desigualdade social, CSES-ESEB 2010

\begin{abstract}
This article investigates the convergence of opinions between Brazilian elites and population about the policies of reduction of poverty and inequality. The international literature is divided in two groups, one that affirms opposite visions between elites and mass towards this issue, and one that sustains that the difficulties that democracies face to reach economic and social development lead to a consensus, in which social policies for poverty reduction are critical. The analysis compares the results from CSES.ESEB 2010 to research data came from an elite survey conducted in 2009. The results support the idea that there is a social consensus between elites and general population.
\end{abstract}

Keywords: elite, population, political agenda, social inequality, CSES-ESEB 2010 


\section{Introdução ${ }^{1}$}

Pobreza e desigualdade econômica e social encontram-se entre as temáticas mais constantes das analisadas da América Latina (ROBERT, 1995); os altos índices de desigualdade colocam a região em foco tanto com relação às políticas governamentais voltadas para a superação da pobreza, como com relação aos efeitos provocados no sistema político e social latino-americano. Essas análises usualmente atribuem aos altos indícies de desigualdade uma série de mazelas do tecido político e social, como a criminalidade, a corrupção e a baixa participação política.

Estudo realizado pelo Programa das Nações Unidas para o Desenvolvimento (PNUD) em 2004 expõe como questionamentos como a desigualdade afeta a consolidação da democracia entre os países latino-americanos e se é possível uma democracia conviver com um sistema social de alta exclusão. 0 estudo ressalta que a região vive um paradoxo, que apesar dos avanços democráticos a partir dos anos 90, as sociedades ainda conviem com alto grau de desigualdade. Os progressos na consolidação democrática ocorreram especialmente na implantação dos processos eleitorais e a transferência de poder tornou-se mais usual. No entanto, apesar dos avanços, a instabilidade ainda persiste em países como Venezuela, Peru e Bolívia. Assim, a instabilidade política é produto do quadro de desigualdades e tensões sociais, que geram pressões centrífugas sobre o sistema político (PNUD, 2004).

Como já foi observado a respeito das democracias recentes (DIAMOND e MORLINO, 2004; ROSE E SHIN, 2001; SCHEDLER E SARSFIELD, 2004), a existência de algumas condições que a literatura reconhece como necessárias ao regime democrático, tais como eleições livres e justas e a garantia algumas liberdades, é insuficiente para assegurar que outros requisitos, tais como o primado da lei e o acesso universal a direitos civis, políticos, sociais e econômicos sejam assegurados. A falta desse conteúdo substantivo pode comprometer a sustentação da própria democracia (MORLINO, 2002). No caso dos países da América Latina, essa situação se agravaria considerando o baixo apoio presente na população aos valores democráticos, que, segundo a literatura, está diretamente ligado ao baixo grau de satisfação com os resultados da democracia (SMITH, 2005). Neste sentido, a consolidação democrática estaria associada ao grau de satisfação com seus resultados econômicos e sociais (ROBERT, 1995; SMITH, 2005).

Em artigo recente, Birdsal e Fukuyama (2011) argumentam que as dificuldades enfrentadas pelas novas democracias para garantir o crescimento

\footnotetext{
${ }^{1}$ As autoras agradecem o CNPQ pelo apoio dado ao ESEB 2010 e à FINEP e FAPESP pelo apoio dado à pesquisa NUPRI 2008.
} 
econômico e desenvolvimento social e os fracos resultados obtidos pelas reformas que se apoiaram no diagnóstico formulado pelas agências internacionais na última década do século passado, sumarizado naquilo que ficou conhecido na literatura como o "Consenso de Washington" (WILLAMSON, 2004), teriam favorecido a formação de um novo consenso social nesses países. No interior desse consenso, as políticas de redução da pobreza e da desigualdade ocupam um lugar preeminente. Para Cleary (2006), entretanto, a centralidade da demanda pela superação da desigualdade social opõe elite e massa, uma vez que o quadro de extrema desigualdade e miséria seria resultado da atitude das elites econômicas que historicamente ignoraram as condições populares e os problemas gerados nesses grupos. Castañeda (2005) propõe a identificar um modelo de centro-esquerda na história recente da América Latina, denominado "Consenso de Buenos Aires", do qual, a questão central está em combinar redistribuição e crescimento econômico mediante uma forte presença do Estado na economia e na sociedade.

Tendo esse pano de fundo, esse artigo verifica em que medida é possível confirmar ou não a existência de um consenso no interior da sociedade brasileira sobre a centralidade da questão do combate à desigualdade. Assim, o artigo busca analisar atitudes e visões das elites e da população brasileiras com relação às políticas de combate à pobreza. A hipótese central afirma essa convergência. Ou seja, seria possível falar em um amplo arco de apoio, unindo boa parte das elites brasileiras e da sociedade em geral, às políticas que visam minorar os impactos mais adversos da extrema pobreza, criar uma rede de proteção mínima para os setores mais frágeis da população e diminuir as diferenças sociais presentes no país. Nesse sentido, elite e opinião pública convergiriam em atribuir grande relevância para a temática redistributiva, sendo possível afirmar a existência de uma visão consensual em torno da busca da igualdade e da justiça social.

Para alcançar esses resultados, o trabalho analisa dados de duas pesquisas: uma realizada em 2008, pelo Núcleo de Pesquisa de Relações Internacionais, junto a membros das elites brasileiras e latino americanas e outra realizada junto à população em geral, em 2010, no âmbito do Estudo Eleitoral Brasileiro, associado ao CSES (Comparative Study of Electoral Systems).

\section{Revisão da literatura}

Este artigo trabalha com o conceito pluralista de elite, o qual supõe que as elites não são um grupo homogêneo e o seu comportamento afeta o processo político (HOLZHACKER, 2006). Diferentemente da perspectiva elitista, que define como elite apenas o seleto grupo dos indivíduos que controlam os espaços de decisão do Estado, a abordagem pluralista define as elites como sendo os 
diferentes grupos que atuam e participam dos assuntos políticos ${ }^{2}$. Os estudos sobre as elites utilizam, assim, os critérios de posição e influência dos atores no processo político decisório (HOFFMANN-LANGE, 1987).

Também é importante ressaltar que este artigo parte do pressuposto que as mudanças recentes ocorridas na economia e na sociedade latino-americana (e brasileira em específico) têm afetado a composição social desses países tornando suas elites mais heterogêneas, com a incoporação de novos grupos e atores. Neste sentido, é possível que as atitudes das elites estejam em processo de mudança, afetando o debate público ${ }^{3}$ e, consequentemente, as atitudes e visões da sociedade em geral. O objetivo deste trabalho não é analisar o grau de influência das elites sobre as atitudes da massa, mas sim de avaliar o grau de convergência e divergência de valores e atitudes manifestados por esses dois grupos com relação à temática da desigualdade.

Os estudos sobre o comportamento das elites na América Latina tendem a focar as preferências econômicas e as posições ideológicas desse setor da sociedade. Busca-se entender o grau de apoio que diferentes setores das elites dão às políticas econômicas, visões favoráveis ou não à internacionalização dos países e à privatização das empresas (ROSAS, 2005). Esses estudos mostram que nos anos 1990 essas elites dividiam-se em dois grupos: um de posição ideológica mais conservadora, que apoiava políticas pró-mercado como a privatização, a abertura de mercados e o Estado Mínimo, e outro que sustentava posições tradicionalmente de esquerda, apoiando uma maior presença do Estado na economia e políticas protecionistas. Rosas (2005), Lima e Cheibub (1994) e Holzhacker (2006) indicam que a dimensão ideológica era central para diferenciar as atitudes das elites brasileiras e latino-americanas no final na primeira década do novo século.

Uma parte importante da literatura também sustenta que o final do período que estamos considerando foi marcado pela presença do debate sobre as estratégias nacionais na mídia, como resultado da ampliação dos canais de

\footnotetext{
20 pressuposto da teoria pluralista é que nem todos participam de forma ativa nos processos de tomada de decisão. Nesta linha, Dahl (1977) mostra que apenas uma parcela restrita dos cidadãos teria uma presença política mais evidente, interessando-se pelas grandes decisões, participando das discussões e das ações. Essa parcela seria o estrato político, por oposição ao apolítico, formado pelo restante dos cidadãos: a maioria. A política, para o primeiro grupo, seria uma referência bastante forte, suas escolhas e estratégias seriam calculadas, racionais, coerentes e consistentes. Para o segundo, a política seria algo distante, e suas escolhas seriam fruto não tanto de um cálculo racional, mas de inércia, hábito, lealdades, vínculos pessoais, emoções e impulsos, e suas orientações seriam desconexas e não-ideológicas.

${ }^{3}$ Estudo realizado nos Estados Unidos mostram que transformações demográficas alteram as atitudes e opiniões dos conjuntos das elites, que passam a incorporar novas dimensões. A ampliação das mulheres e negros nas elites ampliou, por exemplo, o peso das atitudes liberais entre as elites norte-americanas. ROTMAN E BLACK (1999) mostram que também demandas destes novos grupos passaram a ser incorporadas aos dicursos das elites.
} 
participação popular e da consolidação democrática. Neste sentido, as atitudes e visões das elites e sociedade tornam-se mais complexas e diversificada. Para Almeida (2006), esse debate concentrou-se em dois eixos: um nacionaldesenvolvimentista e outro liberal-institucionalista. O primeiro envolveria a combinação de visões nacionalistas, apoio a políticas sociais universais e atitudes pró-crescimento econômico; a segunda dimensão agruparia uma visão favorável à políticas sociais, porém combinadas com políticas econômicas liberalizantes e fortalecimento das instituições políticas, como os partidos e o Congresso. Há um consenso na literatura de que a dimensão da desigualdade deve ser incorporada nas análises sobre as atitudes e opiniões das elites (REIS, 2000). No entanto, não há um consenso sobre a relação que existe entre a questão da desigualdade e o apoio à democracia.

Do ponto de vista da opinião pública, os estudos realizados por Booth e Seligon (2008) mostram que, nos países latino-americanos, o status sócio econômico não é um indicador que tenha impacto significativo na preferência pela democracia ou o grau de engajamento político. Para esses autores, a democracia tornou-se um bem intrínseco à organização social desses países, não sendo vista a partir de uma razão instrumental.

Considerando o impacto da desigualdade sobre o apoio à democracia, Booth e Selignson (2008) comparam os resultados do índice de GINI para diferentes países, para concluir que quanto mais desigual a sociedade, menor o apoio a democracia na população. No entanto, Krishna (2008) e Boix (2003) consideram que não há evidência direta de que maior desigualdade social, por si só, produza uma menor adesão aos valores democráticos. Ainda assim, Krishna considera que as elites, nas sociedades mais desiguais, tenderiam para uma visão instrumental da democracia, favorecendo alternativas não democráticas em determinadas circunstâncias, inclusive porque, segundo essa autora, a consolidação da democracia implicaria em uma maior penetração da agenda pró-políticas distributivas, que conta com um apoio pelo menos frágil junto a essas elites. Essa perspectiva pessimista sustentada por parte da literatura internacional é contradita pelo recente artigo de Birdsall e Fukuyama (2011). Segundo esses autores, as lideranças políticas das novas democracias consolidadas no final do século XX têm perfeita consciência de que a legitimidade desses regimes depende de sua competência para assegurar políticas sociais capazes de reduzir as imensas desigualdades e ampliar a rede de proteção social acessível aos setores mais frágeis dessas sociedades. Da mesma forma, em seu estudo sobre as elites brasileiras, Reis e Chiebub (1995) e Reis (2000) mostram que as questões da pobreza e da desigualdade são temas centrais da agenda política. Para Reis, as elites brasileiras, diferentemente de outros países, não demonstram resistência às 
políticas afirmativas voltadas para minorias, mas indicam preferência para as políticas sociais universais, como ampliação de acesso à saúde e à educação (REIS, 2000).

O estudo de Scalon (2007) confirma um alto grau de convergência entre a elite e a população brasileira em geral com relação ao diagnóstico sobre a natureza da desigualdade econômica e social existente no país. O estudo também mostra que quando confrontados com a dicotomia entre igualdade social (defesa dos benefícios sociais e políticas distributivas) e liberdade individual (relacionada ao individualismo e meritocracia), tanto as elites como a população tendem a aderir mais a visão igualitária. Da mesma forma, os dois grupos convergem para atribuir ao Estado a responsabilidade por políticas que levem à superação das desigualdades.

Entretanto, para Scalon (2007), a eficiência dessas políticas é importante para os dois grupos e afeta o grau de apoio às ações governamentais, levando a que, tanto a população quanto a elite apóiem o aumento dos gastos públicos visando o combate à desigualdade. A elite é mais cética quanto os resultados destes investimentos; já a população é mais otimista sobre a superação das condições sociais e os resultados obtidos pelas políticas redistributivas adotadas pelo Estado. Se, por um lado, elite e povo reconhecem a desigualdade como um problema sério na sociedade, por outro, os dois grupos descrêem nas possibilidades de sua superação apoiada no esforço pessoal dos indivíduos. Por isso, a solução dessa situação depende da ação do governo. O igualitarismo é presente, mas é o Estado que aparece aos olhos de todos como responsável pela sua promoção. Esse estudo corrobora as análises de Castañeda (2005) sobre a construção de um consenso nas sociedades latino-americanas, no qual o Estado tem papel central para a produção do bem estar social.

O survey realizado junto à população foi associado ao Estudo Eleitoral Brasileiro (ESEB), que entrevistou uma amostra aleatória de 2000 eleitores brasileiros em 2010. O ESEB 2010 entrevistou eleitores de 16 anos ou mais no âmbito de uma amostra nacional representativa da população brasileira.

O survey realizado junto às elites foi conduzido em 2008 pelo Núcleo de Pesquisa em Relações Internacionais, no âmbito da pesquisa denominada "As visões das elites latino-americanas sobre a democracia e desigualdade" 4 . A

\footnotetext{
4 As entrevistas ocorreram entre Março e Novembro de 2008, sendo realizadas 95\% das entrevistas previstas. A cada recusa foram realizadas substituições, obedecendo aos critérios previstos inicialmente. As principais dificuldades foram relativas à indisponibilidade de agenda dos entrevistados, sendo este o principal argumento para a recusa entre os entrevistados selecionados. A pesquisa foi desenhada a partir de uma amostra intencional não-probabilística, e seguiu os parâmetros internacionais para definição de erro. A literatura sugere o estabelecimento do indíce de resposta obtido, considerando o número de entrevistas previstas, número de entrevistas realizadas e o número de recusas (WEISBERG, 2005). A
} 
pesquisa realizou 829 entrevistas junto a membros das elites empresariais, partidárias, governamentais, sindicais, intelectuais, e ligadas a movimentos sociais da Argentina, Brasil, Bolivia, Chile, Venezuela e México (HOLZHACKER E ROSSI, 2009). Os entrevistados do Legislativo (Senado e Câmara) foram selecionados entre os participantes das principais Comissões, sendo entrevistados os parlamentares que ocupam a função de Presidente, Vice e/ou Secretário de cada Comissão. Já os entrevistados do Executivo foram escolhidos entre os Ministérios diretamente ligados às políticas públicas de combate à desigualdade, sendo selecionados os assessores diretos dos Ministros e secretários de Governo. Na categoria dos Partidos, foram sorteados senadores e deputados representantes dos 5 partidos de maior representação na Câmara. Os presidentes e membros das executivas desses partidos também foram entrevistados.

A seleção dos empresários foi realizada a partir da consulta e cruzamento das informações divulgadas por veículos de comunicação que apresentam a lista dos empresários mais influentes por setor (por exemplo: Revista Exame, Jornal Valor, Gazeta Mercantil). Assim, chegou-se a uma lista de presidentes, diretores e executivos de grandes empresas. Também foram selecionados os presidentes e diretores das principais organizações empresariais em cada país. Foram selecionados os presidentes e diretores das principais organizações sindicais. Nas categorias jornalistas, intelectuais e ONGs foram realizadas pesquisas junto aos meios de comunicação, como também consulta a outras fontes (por exemplo, participação em fóruns e redes nacionais e internacionais).

Quanto às características socioeconômicas e demográficas, a grande maioria dos entrevistados das elites é do sexo masculino (86,9\%), a idade média dos entrevistados é 52 anos (desvio padrão 11,32) e considerando o grau de escolaridade, 32,2\% possuem ensino superior (completo e incompleto), 25\% possuem pós-graduação lato-sensu ou especialização e $38 \%$ possuem mestrado e doutorado. Apenas 4,6\% dos entrevistados freqüentaram até o ensino médio.

\section{Desigualdade e democracia sob a ótica das elites brasileiras}

Com relação às visões e atitudes das elites brasileiras sobre a o tema da desigualdade e seu impacto nos processos políticos, existe, de um lado, uma forte a adesão à democracia $(97,7 \%$ dos entrevistados opinaram que a democracia é sempre a melhor forma de governo, em qualquer circunstância). Mas, por outro lado, a despeito da alta adesão democrática, a maioria das elites brasileiras

amostra obteve $58 \%$ de indíce de resposta, tendo sendo $72 \%$ o índice de cooperação e $22,5 \%$ o índice de recusa. Consultar a AAPOR website para cálculos de índice de resposta em survey. A amostra distribuiu-se em setores governamentais 20,4\%; partidário, 26,3\%; empresarial, 24,7\%; sindical, 7,2\% e cultuiral-intelectual, $21,5 \%$. 
percebe os limites do arranjo democrático para resolver, por si só, todos os problemas sociais e econômicos que flagelam o continente americano. Assim é que quando inquiridos, $71 \%$ dos entrevistados concordaram pelo menos parcialmente com a colocação de que a "democracia formal não é suficiente para resolver os problemas sociais da América Latina” (Tabela 1)

Tabela 1

Grau de concordância das elites com a afirmativa: "A democracia formal não basta para resolver todos os problemas sociais da América Latina", segundo setores das elites brasileiras

\begin{tabular}{|c|r|r|r|r|r|r|}
\hline & \multicolumn{5}{|c|}{$\%$} & \multirow{2}{*}{ Total } \\
\cline { 2 - 6 } & Governo & Partidos & Empresarios & Sindicatos & $\begin{array}{r}\text { Sociedade } \\
\text { Civil }\end{array}$ & \\
\hline $\begin{array}{c}\text { Discorda } \\
\text { totalmente }\end{array}$ & 11,1 & 22,9 & 37,0 & 13,3 & 13,2 & 21,3 \\
\hline $\begin{array}{c}\text { Discorda } \\
\text { parcialmente }\end{array}$ & 2,8 & 6,3 & 4,3 &, 0 & 21,1 & 7,7 \\
\hline $\begin{array}{c}\text { Concorda } \\
\text { parcialmente }\end{array}$ & 30,6 & 37,5 & 30,4 & 53,3 & 26,3 & 33,3 \\
\hline $\begin{array}{c}\text { Concorda } \\
\text { totalmente }\end{array}$ & 55,6 & 33,3 & 28,3 & 33,3 & 39,5 & 37,7 \\
\hline Total & 36 & 48 & 46 & 15 & 38 & 183 \\
\hline
\end{tabular}

Fonte: NUPRI/USP, 2009

Chi-Square Test: 27,99 , gl: 12 , sig. 0,003

Os baixos índices educacionais e o alto grau de pobreza e desigualdade social são apontados por $81,5 \%$ e $81,9 \%$ dos entrevistados, respectivamente, como os fatores que mais afetam negativamente a democracia em nosso país (Tabela 2). Dessa forma, o argumento de Birdsall e Fukuyama (2011) sobre a mudança de consenso das elites nos países emergentes, com relação à centralidade dos fatores sociais para a sobrevivência da democracia parece ser confirmado pelas posições manifestadas pelas elites brasileiras. De fato, nenhum outro fator alcança igual unanimidade entre os entrevistados. 
BALBACHEVSKY, E.; HOLZHACKER, D. O novo consenso da sociedade brasileira:...

Tabela 2

Fatores que fragilizam nossa democracia, segundo as elites brasileiras.

\begin{tabular}{|l|l|}
\hline & $\begin{array}{l}\text { Concorda } \\
\text { completamente \% }\end{array}$ \\
\hline Baixos níveis educacionais da população & 81,5 \\
\hline Altos níveis de pobreza e desigualdade social & 81,9 \\
\hline Ausência de tradição partidária & 35,5 \\
\hline Grupos e setores da sociedade agindo em causa própria & 51,7 \\
\hline Falta de organização política da população & 61,1 \\
\hline Egoísmo das elites & 58,5 \\
\hline Clientelismo político & 71,8 \\
\hline Falta de crescimento econômico & 41,2 \\
\hline A passividade da população & 56,1 \\
\hline A corrupção do meio político & 75,6 \\
\hline Ameaça de intervenção militar & 44,1 \\
\hline
\end{tabular}

Fonte: NUPRI/USP, 2009

Quando indagados sobre qual deveria ser o principal objetivo do governo (Tabela 3), duas questões tenderam a polarizar as respostas: promover o desenvolvimento e distribuir a riqueza entre toda a população. Como seria de se esperar, as elites sindicais são unânimes em apontar esse último objetivo como o mais relevante, enquanto que os empresários tenderam a enfatizar o desenvolvimento. Entretanto, a grande maioria das elites entrevistadas, independentemente do setor a que pertencem, discordam da proposta de que o desenvolvimento por si só, independentemente de seus impactos sobre a desigualdade social, é um objetivo legítimo. De fato, $86 \%$ dos entrevistados discordaram totalmente da frase "se o país for rico, não importa que existam muita desigualdades econômicas e sociais". Esse padrão de resposta não sofreu nenhuma variação significativa para os diferentes setores das elites. 
Tabela 3

Opiniões sobre o principal objetivo do governo segundo as elites brasileiras

\begin{tabular}{|c|c|c|c|c|c|c|}
\hline \multicolumn{6}{|c|}{$\%$} & \multirow{2}{*}{ Total } \\
\hline & Governo & Partidos & Empresários & Sindicatos & $\begin{array}{c}\text { Sociedade } \\
\text { Civil }\end{array}$ & \\
\hline $\begin{array}{l}\text { Manter a ordem } \\
\text { no país }\end{array}$ & 21,6 & 18,2 & 4,8 & , 0 & 9,4 & 12,7 \\
\hline $\begin{array}{l}\text { Distribuir a } \\
\text { riqueza entre } \\
\text { toda a população }\end{array}$ & 32,4 & 38,6 & 26,2 & 100,0 & 37,5 & 38,0 \\
\hline $\begin{array}{l}\text { Combater a } \\
\text { inflação }\end{array}$ & 2,7 & 6,8 & 2,4 & , 0 & 0 & 3,0 \\
\hline $\begin{array}{l}\text { Proteger a } \\
\text { liberdade de } \\
\text { expressão }\end{array}$ & 5,4 & , 0 & 14,3 & , 0 & 21,9 & 9,0 \\
\hline $\begin{array}{l}\text { Promover o } \\
\text { desenvolvimento } \\
\text { econômico }\end{array}$ & 37,8 & 36,4 & 52,4 & , 0 & 31,3 & 37,3 \\
\hline Total & 37 & 44 & 42 & 11 & 32 & 166 \\
\hline
\end{tabular}

Fonte: NUPRI/USP, 2009

Chi-Square Test: 43,23 , gl: 16, sig. 0,000, células sombreadas são aquelas onde a análise do resíduo ajustado ${ }^{5}$ indica uma associação significativa (positiva ou negativa).

Ademais, uma parte relevante dos entrevistados tende a concordar com o princípio igualitário para a distribuição das riquezas produzidas pela sociedade (Tabela 4). No total, 62,4\% dos entrevistados concordaram ao menos parcialmente com essa idéia, outros 23,1\% manifestaram uma discordância apenas parcial e apenas $22,3 \%$ discordaram frontalmente dessa proposição. Obviamente, a maior

\footnotetext{
${ }^{5}$ Os resíduos ajustados são utilizados para a análise do padrão de inter-relacionamento entre cada uma das categorias de duas variáveis em uma tabela. A base para esse procedimento é a estatística $\chi^{2}$. Por esse procedimento (VALE E SILVA, 1990), calculamos inicialmente o resíduo padronizado da célula, dado por $e_{i j}=\left(n_{i j j} E_{i j}\right) / E_{i j}$ onde nij é o número de casos observados na célula e $E_{i j}$ é o total de casos esperados na célula sendo verdadeira a hipótese nula. Em seguida, ajustamos esse resíduo pela sua variância, estimada por:

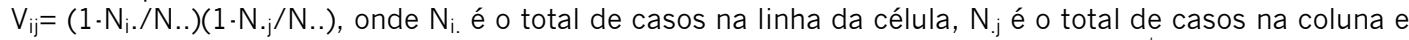
N.. é o total de casos da célula. Assim, o valor do resíduo ajustado é dado por $\mathrm{d}_{\mathrm{ij}}=\mathrm{e}_{\mathrm{ij}} /{ } \mathrm{V}_{\mathrm{ij}}$ Uma vez ajustados, a distribuição de valores dos resíduos distribui-se de acordo com uma curva normal padrão, de média zero e desvio padrão 1,96. Isso significa que, nas células cujo resíduo ajustado, em valor absoluto, é maior do que 1,96, o total de casos observados difere do esperado, sendo verdadeira a hipótese nula, com uma chance de erro menor do que $5 \%$.
} 
resistência a essa proposta se encontra junto aos empresários, onde $43,5 \%$ dos entrevistados manifestaram-se totalmente contrários à idéia. Também aqui, os sindicalistas são o grupo mais favorável, com $85,7 \%$ concordando integralmente com a proposta. Da mesma forma, ao todo, $87,7 \%$ dos entrevistados discordaram da afirmação de que as políticas de distribuição de renda prejudiquem os mais competentes. A distribuição de respostas para essa última questão não sofreu variações significativas para os diferentes setores da elite que estamos considerando.

\section{Tabela 4}

Grau de concordância com a afirmativa: "Tudo o que a sociedade produz deveria ser distribuído entre todos com a maior igualdade possível”, segundo setores da elite brasileira

\begin{tabular}{|l|r|r|r|r|r|r|}
\hline & \multicolumn{5}{|c|}{$\%$} & \multirow{2}{*}{ Total } \\
\cline { 2 - 6 } & Governo & Partidos & Empresários & Sindicatos & $\begin{array}{c}\text { Sociedade } \\
\text { Civil }\end{array}$ & Total \\
\hline $\begin{array}{l}\text { Discorda } \\
\text { totalmente }\end{array}$ & 5,4 & 18,8 & 43,5 &, 0 & 25,6 & 22,3 \\
\hline $\begin{array}{l}\text { Discorda } \\
\text { parcialmente }\end{array}$ & 8,1 & 12,5 & 26,1 &, 0 & 23,1 & 16,3 \\
\hline $\begin{array}{l}\text { Concorda } \\
\text { parcialmente }\end{array}$ & 43,2 & 37,5 & 23,9 & 14,3 & 28,2 & 31,5 \\
\hline $\begin{array}{l}\text { Concorda } \\
\text { totalmente }\end{array}$ & 43,2 & 31,3 & 6,5 & 85,7 & 23,1 & 29,9 \\
\hline Total & 37 & 48 & 46 & 14 & 39 & 184 \\
\hline
\end{tabular}

Fonte: NUPRI/USP, 2009

Chi-Square Test: 55,92, gl: 12, sig. 0,00. células sombreadas são aquelas onde a análise do resíduo ajustado $^{6}$ indica uma associação significativa (positiva ou negativa).

\footnotetext{
${ }^{6}$ Os resíduos ajustados são utilizados para a análise do padrão de inter-relacionamento entre cada uma das categorias de duas variáveis em uma tabela. A base para esse procedimento é a estatística $\chi^{2}$. Por esse procedimento (Vale e Silva, 1990), calculamos inicialmente o resíduo padronizado da célula, dado por $e_{i j}=\left(n_{i j j} \cdot E_{i j}\right) / E_{i j}$ onde nij é o número de casos observados na célula e $E_{i j}$ é o total de casos esperados na célula sendo verdadeira a hipótese nula. Em seguida, ajustamos esse resíduo pela sua variância, estimada por:

$V_{\mathrm{ij}}=\left(1-\mathrm{N}_{\mathrm{i}} / \mathrm{N}_{\mathrm{N}}.\right)\left(1-\mathrm{N}_{\mathrm{j} j} / \mathrm{N} ..\right)$, onde $\mathrm{N}_{\mathrm{i} .}$ é o total de casos na linha da célula, $\mathrm{N}_{\mathrm{j} j}$ é o total de casos na coluna e N.. é o total de casos da célula. Assim, o valor do resíduo ajustado é dado por $\mathrm{d}_{\mathrm{ij}}=\mathrm{e}_{\mathrm{ij}} / \downarrow_{\mathrm{V}} \mathrm{Vj}$ Uma vez ajustados, a distribuição de valores dos resíduos distribui-se de acordo com uma curva normal padrão, de média zero e desvio padrão 1,96. Isso significa que, nas células cujo resíduo ajustado, em valor absoluto, é maior do que 1,96, o total de casos observados difere do esperado, sendo verdadeira a hipótese nula, com uma chance de erro menor do que $5 \%$.
} 
A visão liberal que enfatiza a igualdade de oportunidades como melhor alternativa para a superação das desigualdades tende a ser predominante entre as elites. Quando indagados sobre qual seria a melhor alternativa para combater a desigualdade no Brasil, ao todo, 66,9\% dos entrevistados optaram pela alternativa de "garantir a igualdade de oportunidades", enquanto apenas 22,7\% foram favoráveis a limitar o enriquecimento, e outros 6,7\% optaram por políticas de assistência aos pobres. Mais uma vez, o único setor cujas respostas discrepam significativamente desse padrão são os sindicalistas. Entre os líderes sindicais, $61,5 \%$ consideram prioritária uma política voltada para limitar o enriquecimento, e apenas 38,5\% preferem uma política voltada para garantir a igualdade de oportunidades.

\section{Tabela 5}

Opiniões sobre o que o governo deveria fazer para eliminar as desigualdades do país, segundo as elites brasileiras

\begin{tabular}{|c|c|c|c|c|c|c|}
\hline & \multicolumn{5}{|c|}{$\%$} & \multirow[b]{2}{*}{ Total } \\
\hline & Governo & Partidos & Empresários & Sindicatos & $\begin{array}{c}\text { Sociedade } \\
\text { Civil }\end{array}$ & \\
\hline $\begin{array}{l}\text { Limitar o } \\
\text { enriquecimento } \\
\text { excessivo }\end{array}$ & 25,8 & 14,3 & 7,0 & 61,5 & 35,3 & 22,7 \\
\hline $\begin{array}{l}\text { Garantir a } \\
\text { igualdade de } \\
\text { oportunidades }\end{array}$ & 64,5 & 73,8 & 74,4 & 38,5 & 61,8 & 66,9 \\
\hline $\begin{array}{l}\text { Socorrer os } \\
\text { mais pobres }\end{array}$ & 9,7 & 9,5 & 9,3 & 0 & ,0 & 6,7 \\
\hline $\begin{array}{l}\text { Outras } \\
\text { respostas }\end{array}$ & 0 & 2,4 & 9,3 & 0 & 2,9 & 3,7 \\
\hline Total & 31 & 42 & 43 & 13 & 34 & 163 \\
\hline
\end{tabular}

Fonte: NUPRI/USP, 2009

Chi-Square Test: 29,55, gl: 12, sig: 0,00. células sombreadas são aquelas onde a análise do resíduo ajustado $^{7}$ indica uma associação significativa (positiva ou negativa).

\footnotetext{
${ }^{7}$ Ver nota 6
} 
De maneira geral, portanto, os resultados da análise mostram uma elite preocupada com a dimensão social e os efeitos da desigualdade extrema sobre o sistema político. Há entre as elites uma visão favorável às políticas distributivas desde que garantam um maior acesso aos bens e o desenvolvimento do país. Os dados corroboram parcialmente a análise da literatura, que mostra a centralidade da temática social na agenda das elites nos contextos brasileiros e latino-americano (CASTAÑEDA, 2007; REIS, 2000; SCALON, 2007). Na mesma direção, os dados dessa pesquisa mostram uma elite não avessa às políticas que criam uma rede de amparo social que se contraponha à pobreza extrema; as expectativas de nossa elite vão além desse resultado, apontando para a necessidade de políticas voltadas para garantir a igualdade de oportunidades. Ao todo, 52\% dos entrevistados associam esse resultado à melhoria substantiva da educação, índice que chega a $67 \%$ entre os empresários e $64 \%$ entre os sindicalistas.

\section{Elites e Opinião Pública: convergências e divergências nas opiniões}

A opinião pública e as elites brasileiras mostram atitudes semelhantes sobre políticas voltadas para combater a desigualdade e para a promoção da distribuição de riquezas. De fato, existe no interior da sociedade brasileira uma visão extremamente favorável ao princípio igualitarista, sendo ligeramente maior entre a população. Ao todo, 74,9\% da população concordam (parcialmente ou totalmente) com a idéia de que "tudo que se produz deveria ser distribuído igualmente na sociedade". Esta mesma visão é sustentada por $65,6 \%$ dos membros das elites, como se pode ver na Tabela 6. 


\section{Tabela 6}

Grau de concordância das elites e da população sobre a afirmativa "tudo o que a sociedade produz deveria ser distribuído entre todos com a maior igualdade possível"

\begin{tabular}{|l|r|r|}
\hline & População & \multicolumn{1}{c|}{ Elites } \\
\hline Concorda totalmente & 48.5 & 32.2 \\
\hline Concorda parcialmente & 26.4 & 33.4 \\
\hline Discorda parcialmente & 13.8 & 16.9 \\
\hline Discorda totalmente & 11.3 & 17.4 \\
\hline Total \% & 100 & 100 \\
\hline
\end{tabular}

Fonte: ESEB, 2010, NUPRI, 2009

Essa atitude genericamente favorável ao igualitarismo também se sustenta na discordância com a idéia de que "se o país for rico, pode-se conviver com desigualdades econômicas e sociais", sendo maior entre as elites do que entre a população. Entre a população, embora 54\% discordem totalmente dessa idéia, 28\% concordam pelo menos parcialmente. Já entre os membros da elite, apenas 7,1\% concordam, pelo menos em parte, com essa idéia, e $81,5 \%$ discordam totalmente. (Tabela 7).

Tabela 7

Grau de concordância com a afirmativa "se o país for rico, não importa que haja muitas desigualdades econômicas e sociais", segundo a população geral e as elites brasileiras (\%)

\begin{tabular}{|l|r|r|}
\hline & População & \multicolumn{1}{|c|}{ Elite } \\
\hline Concorda totalmente & 14.1 & 1.7 \\
\hline Concorda parcialmente & 14.0 & 5.4 \\
\hline Discorda parcialmente & 17.9 & 11.5 \\
\hline Discorda totalmente & 54.0 & 81.5 \\
\hline Total \% & 100 & 100 \\
\hline
\end{tabular}

Fonte: ESEB, 2010; NUPRI, 2009 
Os dados apontam que para a maioria da população, apenas a presença de políticas que ampliem a igualdade de oportunidades não é suficiente para combater a desigualdade. É o que sugerem os $68,1 \%$ dos entrevistados da pesquisa ESEB. 2010 que concordam total ou parcialmente que o combate a desigualdade não pode ser apenas voltado para políticas de acesso, mas também devem limitar o enriquecimento dos que ganham mais. Além disso, é preciso ressaltar que o grau de satisfação com a diminuição da desigualdade é relativamente baixo na população brasileira, com apenas $29,4 \%$ dos entrevistados satisfeitos com as políticas de combate à desigualdade.

Ainda com relação ao combate à desigualdade, a população, em sua maioria $(63,7 \%)$, assume posição contrária a diminuição da oferta de serviços públicos em troca de menor cobrança de impostos. As elites também mostram uma prédisposição em aceitar as políticas sociais: $76,4 \%$ discordam que as políticas distributivas prejudicam os mais competentes e 59,3\% são favoráveis ao aumento do gasto público na agenda social, visando o combate à pobreza e desigualdade. Para as elites, as políticas apontadas como importantes para superar a desigualdade, tendem a ter caráter universalista, como ampliação do acesso à educação e à saúde. No caso da população em geral, 47,7\% consideram que o governo gasta pouco na área de social, mas não há uma avaliação direta sobre qual deveria ser a prioridade governamental.

\section{Igualitarismo e voto no eleitorado brasileiro}

Uma última questão a se explorar diz respeito à relevância da temática da superação das desigualdades para o eleitorado brasileiro. A temática da desigualdade e as diferentes alternativas para sua superação foram objeto de pelo menos três questões no questionário utilizado no Estudo Eleitoral Brasileiro de 2010. Tais questões exploram essa temática a partir de ângulos diferentes. A primeira delas aponta a responsabilidade do governo na superação desse problema no Brasil; a segunda explora a necessidade de uma política redistributiva, e, finalmente, a última indaga se o eleitor considera necessário impor limites ao enriquecimento pessoal. A Tabela 8, mostra que essas respostas estão significativamente correlacionadas, e portanto é possível utilizá-las para a construção de uma escala de adesão às políticas redistributivas. 


\section{Tabela 8}

Correlações observadas entre as questões que abordam a temática da erradicação da desigualdade, ESEB 2010

\begin{tabular}{|c|c|c|c|c|}
\hline & & $\begin{array}{l}\text { Tudo que a } \\
\text { sociedade } \\
\text { produz deveria } \\
\text { ser distribuído } \\
\text { entre todos, } \\
\text { com igualdade. }\end{array}$ & $\begin{array}{l}\text { O governo deve } \\
\text { limitar o } \\
\text { enriquecimento } \\
\text { daqueles que } \\
\text { ganham } \\
\text { demais }\end{array}$ & $\begin{array}{l}\text { É obrigação } \\
\text { do governo } \\
\text { diminuir as } \\
\text { diferenças } \\
\text { entre os } \\
\text { muito } \\
\text { pobres e os } \\
\text { muito ricos }\end{array}$ \\
\hline \multirow{2}{*}{$\begin{array}{l}\text { Tudo que a sociedade } \\
\text { produz deveria ser } \\
\text { distribuído entre } \\
\text { todos, com igualdade. }\end{array}$} & Correlação & 1 &, $461\left(^{* *}\right)$ &, $278\left(^{* *}\right)$ \\
\hline & $\begin{array}{l}\text { Significância } \\
\text { (bi-caudal) }\end{array}$ & & ,000 & ,000 \\
\hline \multirow{2}{*}{$\begin{array}{l}\text { O governo deve limitar } \\
\text { o enriquecimento } \\
\text { daqueles que ganham } \\
\text { demais }\end{array}$} & Correlação &, $461\left(^{* *}\right)$ & 1 &, $\left.2122^{* *}\right)$ \\
\hline & $\begin{array}{l}\text { Significância } \\
\text { (bi-caudal) }\end{array}$ & ,000 & & ,000 \\
\hline \multirow[t]{2}{*}{$\begin{array}{l}\text { É obrigação do } \\
\text { governo diminuir as } \\
\text { diferenças entre os } \\
\text { muito pobres e os } \\
\text { muito ricos } \\
\end{array}$} & Correlação &, $278\left(^{* * *}\right)$ &, $212\left(^{* *}\right)$ & 1 \\
\hline & $\begin{array}{l}\text { Significância } \\
\text { (bi-caudal) }\end{array}$ & ,000 & ,000 & \\
\hline
\end{tabular}

Fonte: ESEB 2010

** Correlação significante à 0.01 (bi-caudal).

A escala construída a partir dessas questões atribuiu o valor zero (0) às respostas que indicavam total discordância com a afirmação considerada, valor um (1) às respostas que indicavam alguma discordância (discordo um pouco), valor dois (2), àquelas que indicavam alguma concordância, e o valor 3 para as resposta que indicavam total concordância com a afirmação ${ }^{8}$. 0 valor da escala para cada entrevistado é a somatória dos pontos obtidos a partir de sua resposta a cada

\footnotetext{
8 Para esta escala, não foram considerados os entrevistados que responderam que "não concordavam nem discordavam" da afirmação formulada, e aqueles que não souberam ou não quiseram responder à questão.
} 
BALBACHEVSKY, E.; HOLZHACKER, D. O novo consenso da sociedade brasileira:...

questão. Dessa maneira, a escala varia de zero a nove, sendo o nove alcançado quando o entrevistado declarou sempre sua total concordância à idéia apresentada. Ao todo $30,6 \%$ dos entrevistados foram incluídos nessa posição (valor 9). Essa informação, por si só, é um forte indicativo da relevância da temática da superação da desigualdade para a opinião pública brasileira.

Outra questão relevante é o impacto da dessa dimensão em diferentes setores da sociedade. A Tabela 9 resume os resultados da análise de variância (ANOVA) para algumas variáveis demográficas relevantes:

Tabela 9

Distribuição média da escala de apoio ao combate da desigualdade entre diferentes grupos socialmente relevantes, ESEB 2010.

\begin{tabular}{|c|c|c|c|c|c|}
\hline Variável & Valores & média & $\begin{array}{l}\text { Desvio } \\
\text { padrão }\end{array}$ & $\begin{array}{l}\text { Casos } \\
\text { (total) }\end{array}$ & ANOVA \\
\hline \multirow{6}{*}{ Faixa de idade } & Até 24 anos & 6,7629 & 2,09979 & 291 & \multirow{6}{*}{$F: 0,859$} \\
\hline & 25 a 29 anos & 6,7767 & 2,01778 & 215 & \\
\hline & 30 até 39 anos & 6,8771 & 2,05566 & 358 & \\
\hline & 40 até 49 anos & 6,5805 & 2,27400 & 329 & \\
\hline & 50 anos e mais & 6,7576 & 2,11905 & 458 & \\
\hline & Total & 6,7517 & 2,12092 & 1651 & \\
\hline \multirow{5}{*}{ Renda familiar } & Até 1 salário mínimo & 7,0045 & 2,01251 & 220 & \multirow{5}{*}{ Sig: 0,000} \\
\hline & Mais de 1 SM até 2 SM & 6,9530 & 2,08916 & 489 & \\
\hline & Mais de 2 SM até 5 SM & 6,7468 & 2,13413 & 620 & \\
\hline & Mais de $5 \mathrm{SM}$ & 6,2711 & 2,16144 & 284 & \\
\hline & Total & 6,7607 & 2,12185 & 1613 & \\
\hline \multirow{5}{*}{ Escolaridade } & $\begin{array}{l}\text { Até } 4^{\text {a }} \text { série ensino } \\
\text { fundamental }\end{array}$ & 6,9357 & 2,13183 & 513 & \multirow{5}{*}{$F: 6,278$} \\
\hline & $5^{\mathrm{a}}$ a $8^{\mathrm{a}}$ série, $\mathrm{EF}$ & 6,8098 & 2,14664 & 389 & \\
\hline & $1^{\mathrm{a}}$ a $3^{\mathrm{a}}$ série Ensino Médio & 6,7595 & 2,03399 & 524 & \\
\hline & Ensino superior & 6,2133 & 2,17510 & 225 & \\
\hline & Total & 6,7517 & 2,12092 & 1651 & \\
\hline \multirow{3}{*}{$\begin{array}{l}\text { Identidade } \\
\text { étnica }\end{array}$} & Branco & 6,5801 & 2,11135 & 693 & \multirow[t]{3}{*}{$F: 7,849$} \\
\hline & Outras etnias & 6,8758 & 2,12027 & 958 & \\
\hline & Total & 6,7517 & 2,12092 & 1651 & \\
\hline
\end{tabular}

Fonte: ESEB 2010 
Como é possível observar na Tabela 9, a idade não produziu variações significativas no padrão de resposta a cada grupo, tendo se mantido mesmo quando se controlou a faixa de renda familiar do entrevistado. Por outro lado, há uma diferença pequena, porém significativa, nas outras variáveis consideradas, que segue o padrão esperado, qual seja, os mais pobres, não brancos e menos escolarizados tendem a ser, em média, mais favoráveis a políticas dessa natureza do que os mais ricos, brancos e mais escolarizados. Entretanto, cabe ressaltar que as diferenças observadas são muito pequenas, o que mais uma vez reforça o argumento apresentado acima, de que a questão da desigualdade é uma preocupação de fundo em nossa sociedade, e que as políticas que combatem esse problema encontram amplo apoio em todos os grupos sociais.

A Tabela 10 mostra o impacto da escala de apoio às políticas de combate à desigualdade sobre o processo eleitoral.

Tabela 10

Distribuição média da escala de apoio às políticas de combate à desigualdade para diferentes dimensões do processo político-eleitoral

\begin{tabular}{|c|c|c|c|c|c|}
\hline Variável & Valores & média & $\begin{array}{l}\text { Desvio } \\
\text { padrão }\end{array}$ & $\mathrm{N}$ & ANOVA \\
\hline \multirow{3}{*}{$\begin{array}{l}\text { Algum partido } \\
\text { representa o } \\
\text { eleitor? }\end{array}$} & Sim & 6,7979 & 2,14308 & 678 & \multirow[t]{3}{*}{$F: 0,958$} \\
\hline & Não & 6,6928 & 2,11654 & 931 & \\
\hline & Total & 6,7371 & 2,12773 & 1609 & \\
\hline \multirow{6}{*}{$\begin{array}{l}\text { Qual partido } \\
\text { melhor } \\
\text { representa o } \\
\text { eleitor }\end{array}$} & PT & 6,9353 & 2,09467 & 417 & \multirow{6}{*}{$\begin{array}{l}F: 1,828 \\
\text { Sig. } 0,122\end{array}$} \\
\hline & PSDB & 6,5810 & 2,19607 & 105 & \\
\hline & PMDB & 6,6222 & 2,42420 & 45 & \\
\hline & PV & 6,8095 & 1,85661 & 63 & \\
\hline & outros & 6,1190 & 2,52985 & 42 & \\
\hline & total & 6,7961 & 2,14770 & 672 & \\
\hline \multirow{5}{*}{$\begin{array}{l}\text { Avaliação do } \\
\text { governo Lula } \\
\text { nos últimos } 4 \\
\text { anos }\end{array}$} & Muito bom & 6,8404 & 2,17316 & 545 & \multirow{5}{*}{$F: 2,361$} \\
\hline & Bom & 6,7623 & 2,07177 & 993 & \\
\hline & Ruim & 6,2800 & 2,17206 & 75 & \\
\hline & Péssimo & 6,0833 & 2,53526 & 24 & \\
\hline & Total & 6,7563 & 2,12042 & 1637 & \\
\hline \multirow{4}{*}{$\begin{array}{l}\text { Escolha } \\
\text { eleitoral, } \\
\text { primeiro turno }\end{array}$} & Dilma & 6,9651 & 2,00908 & 745 & \multirow{4}{*}{$\begin{array}{l}F: 4,816 \\
\text { Sig: 0,002 }\end{array}$} \\
\hline & Serra & 6,6368 & 2,18532 & 435 & \\
\hline & Marina & 6,5176 & 2,19292 & 284 & \\
\hline & Outros & 7,5294 & 1,69991 & 17 & \\
\hline
\end{tabular}


BALBACHEVSKY, E.; HOLZHACKER, D. O novo consenso da sociedade brasileira:...

\begin{tabular}{|c|c|c|c|c|c|}
\hline & Total & 6,7893 & 2,10313 & 1481 & \\
\hline \multirow{3}{*}{$\begin{array}{l}\text { Escolha } \\
\text { eleitoral, } \\
\text { segundo turno }\end{array}$} & Dilma & 6,9303 & 2,04938 & 875 & \multirow[t]{3}{*}{$F: 11,163$} \\
\hline & Serra & 6,5496 & 2,20028 & 564 & \\
\hline & Total & 6,7811 & 2,11723 & 1439 & \\
\hline \multirow{4}{*}{$\begin{array}{l}\text { Satisfação com } \\
\text { a diminuição da } \\
\text { desigualdade }\end{array}$} & Muito insatisfeito & 6,9794 & 2,04498 & 681 & \multirow[t]{4}{*}{$F: 8,087$} \\
\hline & Satisfeito & 6,5202 & 2,18258 & 694 & \\
\hline & Muito satisfeito & 6,7254 & 2,13592 & 244 & \\
\hline & Total & 6,7443 & 2,12789 & 1619 & \\
\hline \multirow{4}{*}{$\begin{array}{l}\text { Satisfação com } \\
\text { os gastos } \\
\text { sociais do } \\
\text { governo }\end{array}$} & Gasta muito & 6,5815 & 2,25682 & 399 & \multirow[t]{4}{*}{$F: 3,804$} \\
\hline & Gasto adequado & 6,5667 & 2,09416 & 360 & \\
\hline & Gasta pouco & 6,8710 & 2,07457 & 806 & \\
\hline & Total & 6,7272 & 2,13072 & 1565 & \\
\hline \multirow{3}{*}{$\begin{array}{l}\text { Apoio à } \\
\text { democracia }\end{array}$} & $\begin{array}{l}\text { Democracia é a melhor } \\
\text { forma de governo }\end{array}$ & 6,6677 & 2,14058 & 1312 & F: 1,018 \\
\hline & $\begin{array}{l}\text { As vezes a ditadura pode } \\
\text { ser melhor, tanto faz }\end{array}$ & 6,8217 & 2,11223 & 230 & \multirow[t]{2}{*}{ Sig: 0,313} \\
\hline & total & 6,6907 & 2,13640 & 1542 & \\
\hline
\end{tabular}

Fonte: ESEB 2010

A Tabela 10 indica que os seguintes aspectos, ter ou não identidade com algum partido, o partido específico que o eleitor escolhe para representá-lo e a avaliação que o eleitor faz do governo Lula são dimensões que não produzem variações significativas na distribuição da escala de apoio às políticas de combate à pobreza e desigualdade social. Da mesma forma, não há uma correlação significativa entre essa escala e o auto-posicionamento do eleitor na escala ideológica $\left(R^{2}=0,008\right.$, sig: 0,825).

Entretanto, a posição do eleitor com relação a essa dimensão teve algum impacto - ainda que pequeno - sobre a sua escolha eleitoral, tanto no primeiro turno quanto no segundo turnos. De fato, entre os eleitores da candidata da coalizão governista - Dilma Rousseff - cresce significativamente o apoio a essas políticas. Da mesma forma, quando consideramos as opiniões e atitudes dos eleitores em relação a outras dimensões da vida política, constatamos que esta escala não guarda qualquer associação significativa com a questão da democracia, mas varia significativamente com a avaliação que o eleitor tem sobre as políticas do governo no combate à desigualdade social. De maneira geral, a crítica ao sucesso do governo nessa área está significativamente associada a uma posição mais extrema na escala de apoio à políticas de combate à desigualdade. 
Mais uma vez, entretanto, as diferenças são pequenas, o que concorre para a hipótese geral desse trabalho de que a questão do combate à desigualdade se converteu em uma questão central para a agenda política do país, tanto aos olhos da elite quanto nos olhos da população, que vêem no governo o principal ator na promoção de políticas capazes de mudar significativamente essa realidade.

\section{Conclusão}

Este trabalho investigou o grau de convergência das opiniões sustentadas pelas elites e pela população brasileira sobre as políticas de redução da desigualdade social e redução da pobreza. A literatura internacional sobre esse tema divide-se entre aqueles que vêem uma divisão entre elite e massa em torno dessa questão, e aqueles que, tal como expresso por Birdsal e Fukuyama (2011), supõem que as dificuldades enfrentadas pelas novas democracias para garantir o crescimento econômico e desenvolvimento social teriam favorecido a formação de um novo consenso social unindo elites e massas, no qual as políticas de redução da pobreza e de desigualdade ocupam um lugar preeminente. A análise comparou os resultados alcançados no Estudo Eleitoral Brasileiro (ESEB) de 2010, com os dados coletados junto a uma amostra da elite brasileira em 2009, com o objetivo de estabelecer uma possível convergência entre setores da elite e opinião da população brasileira sobre políticas sociais voltadas para a diminuição da desigualdade e erradicação da pobreza. Os resultados da análise indicam alguns pontos importantes.

O primeiro, convergindo com o diagnóstico apresentado por Birdsal e Fukuyama (2011), é possível observar um amplo consenso tanto na opinião pública como na elite brasileira em torno da necessidade de políticas que enfrentem os problemas sociais e políticos associados à imensa desigualdade social que caracteriza a sociedade brasileira.

Em segundo lugar, tanto entre os membros da elite como entre a população em geral o Estado é visto como protagonista por excelência no processo que leva à erradicação da pobreza e à diminuição da desigualdade.

Além disso, o consenso observado constrói-se em torno de uma perspectiva igualitária, que refuta com veemência a perspectiva de um crescimento sem maior justiça social, e que oferece amplo apoio para políticas redistributivistas.

Com relação às elites, encontramos que 0 apoio às políticas redistributivistas está associado à perspectiva liberal que propõe reduzir as desigualdades mediante a oferta de políticas que promovam uma igualdade de oportunidades. Nessa perspectiva, a educação é percebida como um instrumento por excelência para se alcançar esse resultado. 
Com relação à população, encontramos que o apoio às políticas redistributivistas está associado à uma demanda igualitária, que não apenas refuta a hipótese de crescimento sem igualdade, mas também empresta apoio à iniciativas que limitem a afluência da parcela mais rica da sociedade.

Finalmente, encontramos que, embora o apoio às políticas de erradicação da miséria e de diminuição da desigualdade não esteja associado à orientação partidária do eleitor, essa questão teve um impacto significativo na sua decisão eleitoral e influencia a sua avaliação sobre o desempenho do governo nessa dimensão.

\section{Referências Bibliográficas}

ALMEIDA, P. R. "América Latina: novo rumo em direção à esquerda?" Carta Internacional, vol.1, n 1 , p. 3-5, 2006.

BIRDSALL, N. "From Social Policy to an Open-Economy Social Contract in Latin America". Center for Global Development: Working Paper, $\mathrm{n}^{\circ} 21$. Disponível em:

$<$ http://economics.ucr.edu/seminars/fall05/ped/NancyBirdsall11-18-2005.pdf>, 2002.

BIRDSALL, N.; FUKUYAMA, F. "The Post-Washington Consensus". Foreign Affairs, vol. 90, $\mathrm{n}^{\circ} 2$, p. $45-53,2011$.

BOIX, C. Democracy and Redistribution. Cambridge: Cambridge University. Press, 2003.

BOOTH, J. A.; SELIGSON, M. Inequality and Democracy in Latin America: individual and context effects of welth on political participation. In: KRISHNA, A. (ed.). Poverty, Participation, and Democracy. Cambridge: Cambridge University Press, p. 94-124, 2008.

CASTAÑEDA, J. G. “Latin America's Left Turn”. Foreign Affairs, vol. 85, n 3, p. 28.43, mayjune, 2006.

CLEARY, M. R. “A 'left turn' in Latin America? Explainging the left's resurgence”. Journal of Democracy, vol. 17, $\mathrm{n}^{\circ}$ 4, p.35-49, 2006.

DAHL, R. Um prefácio à teoria democrática. Rio de Janeiro: Zahar, 1977.

DE SWAAN, A. In care of the state. (Health care, education and welfare in Europe and the USA in the modern era). Cambridge; Polity Press, 1988. 
DIAMOND, L. e MORLINO, L. "The Quality of Democracy". Journal of Democracy, vol. 15, n 4, p. 20-31, 2004.

HOFFMANN-LANGE, U. Surveying National Elites in the Federal Republic of Germany. In: MOYER, G; WAGSTAFFE, M. (eds.). Research Methods for Elite Studies, Boston: Allen \& Unwin, 1987.

HOLZHACHER, D. Atitudes e percepções das elites e da opinião pública sobre a política externa brasileira nos anos 90. Tese de Doutoramento: Departamento de Ciência Política, Universidade de São Paulo, 2006.

South American Elite Views on Democracy and Inequality: A comparative perspective. observatory on structures and institutions of inequality in Latin America. Working Paper Series $\mathrm{N}^{\circ} 28,2010$.

HOLZHACKER, D; ROSSI, F. "As visões das elites sulamericanas e mexicanas a respeito da democracia e da desigualdade social e econômica". Carta Internacional, vol. 4, n² 2, p. 53.73, 2009.

HUNTER, W. e POWER, T. J. "Lula's Brazil at Midterm" Journal of Democracy, vol. 16, n 3, p. 127-139, 2006.

KINGSTONE, P. "Elites, democracy, and market reforms in Latin America". Latin American Politics \& Society, vol. 43, n 3, p.139-142, 2001

KRISHNA, A. Introduction: poor people and democracy. In: KRISHNA, A. (ed.). Poverty, Participation and Democracy. Cambridge: Cambridge University Press, p. 1-27, 2008.

LIMA, M. R. S.; CHEIBUB, Z. B. Elites estratégicas e dilemas de desenvolvimento. Rio de Janeiro: IUPERJ, 1994.

MORGAN, J.; KELLY, N. "Explaining Public Attitudes toward fighting inequality in Latin America", Poverty \& Public Policy, vol. 2, n 3, 2010

MORLINO, L. "What is a Good Democracy". Democratization, vol. 11, n 5, p. 10-32, 2002.

MUNCK, G. L. "Democratic politics in Latin America: New debates and research frontiers". Annual Review of Political. Science, vol.7, n 1, p.437-62, 2004.

REIS, E. P. "Percepções das elites sobre a pobreza e a desigualdade". Revista Brasileira de Ciências Sociais, vol. 42, nº 15, p.143-152, 2000.

REIS, E. P. e CHEIBUB, Z. B. "Valores políticos das elites e consolidação democrática". Dados - Revista de Ciências Sociais, vol. 38, nº 1, p. 31-56, 1995.

ROBERTS, K. "Neoliberalism and the transformation of populism in Latin America: the Peruvian case". World Politics, vol. 48, n 1, p. 82-116, 1995.

ROSAS, G. "Preferences The Ideological Organization of Latin American Legislative. Comparative Political Studie, vol. 38, n 7, p. 824-849, sept. 2005. 
ROSE, R. e SHIN, D. C. "Democratization backwards: the problem of third wave democracies". British Journal of Political Science, vol. 31, n² 2, p. 331-354, 2001.

ROTHMAN, S.; BLACK, A. "Elites Revisited: American social and political leadership in the 1990s" International Journal of Public Opinion Research, vol. 11, n² 2, p. 174-195, 1999.

SCALON, C. "Justiça como igualdade? A percepção da elite e do povo brasileiro". Sociologias, vol. 9, n 18, p. 126-149, 2007.

SCHEDLER, A., SARSFIELD, R. "Democrats with adjectives: Linking direct and indirect measures of democratic support". Afrobarometer Working-paper, n 45, 2004.

SMITH, P. H. 2005. Democracy in Latin America: political change in comparative perspective. Oxford: Oxford University Press, 2005.

UNDP - United Nations Development Programme. A democracia na América Latina. rumo a uma democracia de cidadãs e cidadãos. São Paulo: PNUD, 2004.

VALLE E SILVA, N. Introdução à análise de dados qualitativos. Rio de Janeiro: Vértice Universitária, 1990.

WEISBERG, H. F. The Total Survey error approach: (a guide to the new science of survey research). Chicago: The University of Chicago Press, 2005.

WILLIAMSON, J. A Short History of the Washington Consensus. In: Conference From the Washington Consensus towards a new Global Governance, 24.25 sept. 2004, Barcelona.

Elizabeth Balbachevsky - balbasky@usp.br

Denilde Holzhacker - denildeh@uol.com.br

Recebido para publicação em setembro de 2011 Aprovados para publicação em outubro de 2011 